\title{
The Analysis of Active Power Control Requirements in the Selected Grid Codes for Wind Farm
}

\author{
Mi-Young Kim ${ }^{\dagger}$ and Yong-Un Song*
}

\begin{abstract}
The renewable energies such as photovoltaic power, wind power and biomass have grown to a greater extent as decarbonization techniques. The renewable energies are interconnected to power systems (or electrical grids) in order to increase benefits from economies of scale, and the extra attention is focused on the Grid Code. A grid code defines technical parameters that power plants must meet to ensure functions of power systems, and the grid code determined by considering power system characteristics is various across the country. Some TSO (Transmission System Operator) and ISO (Independent System Operator) have issued grid code for wind power and the special requirements for offshore wind farm. The main purpose of the above grid code is that wind farm in power systems has to act as the existing power plants. Therefore wind farm developer and wind turbine manufacturer have great difficulty in grasping and meeting grid code requirements. This paper presents the basic understanding for grid codes of developed countries in the wind power and trends of those technical requirements. Moreover, in grid code viewpoint, the active power control of wind power is also discussed in details.
\end{abstract}

Keywords: Grid code, Wind Power Generator (WPG), Wind Power Plant (WPP), Active power control, Frequency control

\section{Introduction}

The sizeable penetration of renewable energies to electrical grid is not unfamiliar to us in technical and economical views as countermeasures solving climate change and energy problems (security and demand). The renewable energies introduction increasing has highlighted a grid code because intermittent natural source. The power plant must not hinder grid functions, and grid code defines technical requirements to keep functions. Grid codes are different because grid characteristics are various across the country. Some TSO and ISO have presented grid code for wind power and the special requirements for offshore wind power with generally large size. Through grid code, the electrical grid stability can be maintained even if the large size wind farms are introduced into electrical grid. Absolutely, every power plant including renewable energies has to comply with the grid code to sell electricity to utilities. Therefore, a well-defined grid code shall be presented so as that there is no interpret the grid code by manufacturer, developer and TSO.

Meanwhile, IEC 61400-22 "Wind turbines - Part 22: Conformity testing and certification" defines rules and procedures for a certification system for wind turbines. IEC 61400-22 specifies requirements for carrying out

$\dagger$ Corresponding Author: New \& Renewable Energy Team, Innovation KR, Korea. (mykim@innovationkr.com)

* New \& Renewable Energy Team, Innovation KR, Korea. (songye@ innovationkr.com)

Received: November 20, 2013; Accepted: February 23, 2015 conformity evaluation of type characteristics measurements (incl PQ(Power Quality) and LVRT(Low Voltage Ride Through)) in type certification and project characteristics measurements (incl Grid connection compatibility according to grid codes) in project certification procedures. Grid connection compatibility is mandatory in most countries in spite of optional requirements in IEC 61400-22.

There are about 119 grid codes in the world from IGCC_GLWind_Rev.7 issued in March 2013. The different grid code according to energy sources (wind, PV, biomass etc.) connected to power system has been built. The bestknown grid codes have been issued in countries that have many experiences of installing and operating wind farms onshore / offshore, which the representative grid codes are from German TSO Tennet, Danish TSO Energinet and UK TSO national grid, etc. Besides, the international organization, the local association, certification body, testing laboratory and TSO / ISO are having rules verifying grid code compatibility, which the organizations are German FGW (Forschungsgemeinschaft Werkzeuge und Werkstoffe e.V.), FGH (Forschungsgemeinschaft fur Elektrische Anlagen und Stromwirtschaft e.V.), DNV-GL and Spanish Red Electrica de Espana, etc.

The study to develop, amend or update grid code has been discussed in several papers. Experience and knowledge from countries with wind integration experience are introduced in [1]. However, this book didn't include grid code trends and detail explanations using figures for active power control, which can help making technical requirements in countries that grid-connected wind power 
is less. Grid code summary was studied to revise technical and regulatory exigencies for grid integration of wind generation into the Argentina electrical grid in [2]. The reviewing the main problems of the connection of wind farms to the grid and how the grid codes must be adapted in order to integrate wind power generation capacity without affecting the quality and stability of the grid was explained in [3]. In particular, the compliance of large offshore wind farms employing DFIGs with the GB Grid Code reactive power requirement was examined with the help of simulations in [4]. Establishment of grid code for wind generation and development of coordinated operation schemes of Jeju power system was presented in [5]. Two work packages(WP) undertaken by ECAR Ltd. for AEMO (Australian Energy Market Operator) show international practice and a general review of technical issues in WP1 and review of international grid code in WP2 [6]. The paper [7] describes the rules regarding grid connection in different countries and assesses the future impact of offshore wind power on the western French grid. Dynamic performance of DC connected wind farm is evaluated and VSC-based HVDC system is investigated in [8]. In active power regulation of wind farm, an overview of basic wind turbine control systems and those recent trends for frequency stability are provided in [9]. The paper [10] studied the grid requirements in Denmark and China regarding regulations of active power control, reactive power control and LVRT capability. This paper presents the basic understanding for grid codes of developed countries in the wind power field and trends of those technical requirements. This study can help wind farm developer and wind turbine manufacturer that have great difficulty for grid code requirements. Moreover, the direction to prepare high level penetration of wind power in grid code viewpoint is discussed.

\section{Grid Code and Related Standard}

As is known, the representative grid codes have been issued from German TSO “Tennet”, Danish TSO "Energinet" and UK TSO "national grid", etc. These TSOs are the most actively introducing wind farms into electrical grid. Here are some details for each grid code properties.

\subsection{Energinet grid code}

The latest Danish grid code "Technical regulation 3.2.5 (TF 3.2.5) for wind power plants with a power output greater than $11 \mathrm{~kW}$ " was published in Dec, 2010 and superseded existing grid codes according to voltage levels connected with wind power [11]. Otherwise the latest TF 3.2.5 are divided in relation to the connected rated power (11kW $\sim 25 \mathrm{~kW}, 25 \mathrm{~kW} \sim 1.5 \mathrm{MW}, 1.5 \mathrm{MW} \sim 25 \mathrm{MW}$, exceed $25 \mathrm{MW}$ ) at PCC (Point of Common Coupling). The requirements specified in TF 3.2 .5 consist of tolerance of

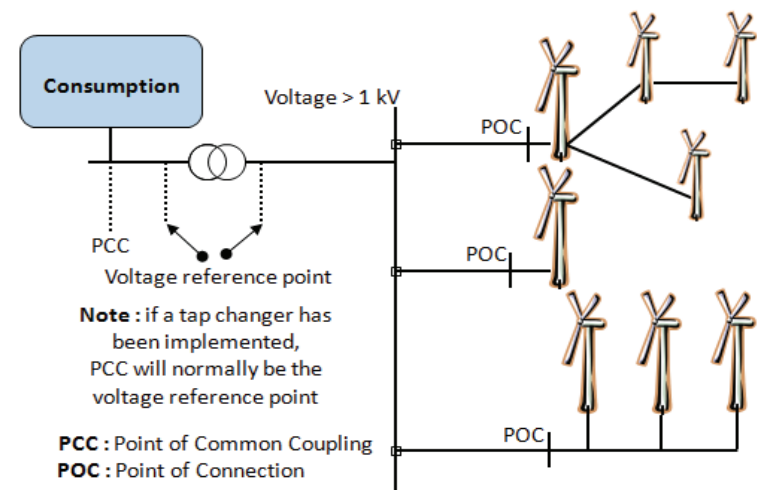

Fig. 1. Typical grid connections of wind power plants

frequency and voltage deviations, electricity quality, control and monitoring, protection, data communication and exchange of signals, verification and documentation, etc. Major differences with other grid codes are as follows. (1) Requirements for steady and dynamic states do not be included separately in grid code. (2) Active power regulation, LVRT capacity and dynamic reactive power regulation requirements are included in tolerance requirement of frequency and voltage deviations. Moreover, active power control and reactive power control requirements are included in control and monitoring. (3) This TF 3.2.5 applies same requirements to onshore and offshore wind farms. (4) The typical grid connections of wind power plants, PCC and POC, are displayed as Fig. 1.

\subsection{Tennet grid code}

The latest German (Tennet) grid codes for wind farm were published in Dec, 2012 and are almost same with existing e'on grid code: "High and extra high voltage" for wind farm onshore and "Requirements for Offshore Grid Connections in the Grid of TenneT TSO GmbH" for wind farm offshore [12-13]. Requirements specified in Tennet grid codes consist of active power output, frequency stability, reactive power exchange and voltage stability, disconnecting the generating plant from the grid, behavior during grid disturbances, electrical protection, Restoration of supply, Connection technology, power system management, etc. Major differences with other grid codes are as follows. (1) Overall, the requirements for steady and dynamic states are included separately in grid code. (2) Grid codes are classified for wind farm onshore/offshore and offshore grid code is more severe. (3) Grid code is composed of requirements on all connecters, generating plant and REA generating plants. (4) Some requirements are different according to Type 1 and Type 2 generating plants. A Type 1 generating plant refers to a synchronous generator connected directly to the grid and the others are Type 2 .

\subsection{SDL grid code}

The new German grid regulation was issued to stabilize 
the national grid by increasing amount of installed wind turbines and the requirements are mandatory for all wind turbine generators (WTGs) which will be connected to the grid after Jun, 2011 [14]. The requirements specified in SDL grid codes consist of FRT (Fault-Ride-Through), active power feed-in, reactive power feed-in, reactive current feed-in during grid fault, voltage variations, etc. Major differences with other grid codes are as follows. (1) This SDL grid code states new requirements that wind turbines can behave as a conventional power plant. (2) For the service of supporting grid stability, the wind farm operator will be rewarded with an extra bonus. The supporting documents as follows are needed for this bonus: unit certificate for single wind turbine, wind farm certificate and third party approval. (3) The requirements for steady and dynamic states do not be included separately in grid code. (4) This TF 3.2.5 applies same requirements to onshore and offshore wind farms. (5) SDL grid code is classified into "medium voltage requirements" and "high voltage requirements" according to voltage levels interconnected with wind farm.

\subsection{Korean grid code}

Korean grid code "The provision for using transmission and distribution systems" was published in Jun, 2010 and amended in Jan, 2013 [15]. The requirements for renewable plants are specified in annex 6 and are divided according to voltage levels with renewable plants. This provision is applicable to all renewable energies regardless of sources. "The standard for electrical power system reliability and power quality" was also published in Apr, 2012 and the requirement for renewable plant is specified chapter 8 [16]. These grid codes are applied to renewable plants exceeding the rated power $20 \mathrm{MW}$ in region except Jeju Island. The requirements consist of generator type, grid connection method, LVRT, reactive power capacity, active power control, frequency control, power quality, etc. Major differences with other grid codes are as follows. (1) The requirements for steady and dynamic states do not be included separately in grid code. (2) The core conditions, active power regulation and minimum duration time, do not be stated in tolerance requirement of frequency and voltage deviations. (3) Korean grid code applies same requirements to onshore and offshore wind farms. (4) The detail explanations for grid code must be improved.

\subsection{Grid code trends}

The technical superior grid codes being applied to wind farm onshore and offshore were developed in countries that wind farm is largely connected to grid. The other countries such as Philippine, Saudi Arabia, South Africa, and Jordan were modified with Energinet and Tennet grid codes. Moreover the grid code of national grid is similar with Irish and Scottish grid codes. The grid code is constructed with steady state and dynamic state requirements. The steady state requirements are relevant to behavior characteristics and power flow at PCC, and dynamic state requirements are related to operation and measurement. The trends of grid code are as follows.

- According to energy sources (photovoltaic, wind, ocean energy), the different grid codes are applied.

- In same grid code, the requirements applied to connection voltage levels (transmission system and distribution system) are different.

- The different requirements according to wind farm capacities are applied in same grid.

- There are the different requirements to the connected generator types (synchronous and asynchronous) in the same grid code.

- Requirements for wind farm installing locations (onshore and offshore) are not same. Those for wind farm offshore are more severe than land.

- The international standards such as IEEE and IEC are generally applied for power quality; however the more strong requirements are applied in some country.

- Grid code is also progressed according to technology progress of wind turbine, and the different requirements are presented for wind farm performance. That is, wind farm developer has a wide choice due to many optional requirements. When wind farm can be got an additional price bonus though satisfying the progressed grid code.

- Wind farm with rated wind speed cannot supply full power to satisfy grid code from time to time, and non-

Table 1. Generic grid code format for wind power plants

\begin{tabular}{|c|c|}
\hline Classification & Requirements \\
\hline \multirow{6}{*}{ Steady state performance } & Frequency, voltage and power rating \\
\hline & Frequency rating \\
\hline & Voltage rating \\
\hline & Power rating \\
\hline & Reactive power rating \\
\hline & Power quality parameters \\
\hline \multirow{13}{*}{$\begin{array}{c}\text { Dynamic } \\
\text { performance }\end{array}$} & Frequency gradients and power ramp rates \\
\hline & Start-stop and islanding with load requirements \\
\hline & Control of active power \\
\hline & Run-back \\
\hline & Frequency control \\
\hline & Inertial response \\
\hline & $\begin{array}{l}\text { Controls utilizing the reactive power capability } \\
\text { of the wind power plant }\end{array}$ \\
\hline & Power factor control mode \\
\hline & Reactive power control mode \\
\hline & Voltage control mode \\
\hline & Fault ride-through(FRT) \\
\hline & Temporary overvoltages(TOV) \\
\hline & System and relay protection \\
\hline \multirow{2}{*}{$\begin{array}{l}\text { Communication and } \\
\text { control interface }\end{array}$} & Plant status information \\
\hline & Meteorological information \\
\hline \multirow{5}{*}{$\begin{array}{c}\text { Simulation models, } \\
\text { certification/verification, } \\
\text { commissioning and } \\
\text { performance } \\
\text { verification }\end{array}$} & Integration and design simulation models \\
\hline & System planning simulation models \\
\hline & Certification/verification \\
\hline & Commissioning \\
\hline & Performance testing \\
\hline
\end{tabular}


supplied power output is compensated with using the measured wind speed.

- The grid code includes descriptions, figures, equations, values, verification procedures and related documents to promote a better understanding to wind farm developer.

- Wind farm developer can make sense of grid code through well written term definitions.

- It is expected to apply the different grid code to HVAC (High Voltage Alternating Current) and HVDC (High Voltage Direct Current) connection methods.

- A stay period and effective period are specified in grid code.

\subsection{Technical requirements in grid code}

For wind farm grid connection, the common requirements in grid codes are as follows. In 2007, EWEA (European Wind Energy Association) working group was started to make European grid code for large wind farm and presented the grid code structure [17].

- Active power control: The requirements are needed to secure grid frequency and the different requirements are specified in each grid code because of considering energy mix condition, grid characteristic, etc. Details are shown in section 3 .

- Reactive power control (incl FRT requirement): The requirements are needed to secure grid voltage and are different by TSO or country. For example, Energinet is demanding all $\mathrm{Q}$ control, power factor control and voltage control functions.

- Power quality: Generally, the international standards are applied to grid codes, however, Energinet grid code is more severe.

- Protection system: wind farm must be protected against damage due to grid faults and incidents. The settings and function times for overvoltage, undervoltage, overfrequency, underfrequency is presented in grid code.

- Data communication and exchange of signals: The communication between wind farm operator and TSO must be prepared. The information and signal for wind farm must be transferred to TSO in order to operating grid.

- Verification and documentation: Wind farm owner must submit simulation models and validation reports for wind turbine and farm, which are used to ensure that wind farm meets grid code.

\section{Active Power Control Requirements}

The active power output of wind farm must be controlled to tolerate voltage and frequency deviations, control over frequency and be constrained considering power system state. The detail explanations for active power control in each grid code are as follows.

\subsection{Frequency and voltage deviations}

When voltage (absolute value) and frequency (absolute value) deviations are occurred at PCC, wind farm must remain connected to power systems in accordance with protective functions. In every grid code, voltage and frequency variations are defined as limit value to disconnect, and the operating area for active power output can be determined with voltage, frequency and duration time.

\subsubsection{Energinet grid code}

The voltage operation range is specified in minimum and maximum limits from nominal voltage. The different operating area for active power output is applied according to wind farm capacity. Fig. 2 shows operating area for active power output with wind farm capacity $(>25 \mathrm{~kW})$. In under and over frequency at PCC, the active power output can be controlled to the minimum limit that power output below limit cannot be allowed. In Fig. 2, if the frequency range is $47 \sim 47.5 \mathrm{~Hz}$ and voltage range is $0.9 \sim 1.05$ (p.u.) at

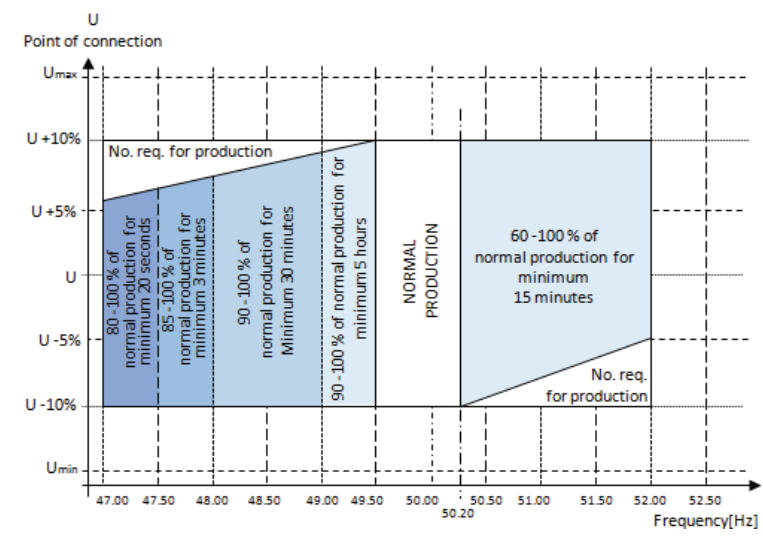

Fig. 2. Requirement for active power output with wind farm capacity $(>25 \mathrm{~kW})$
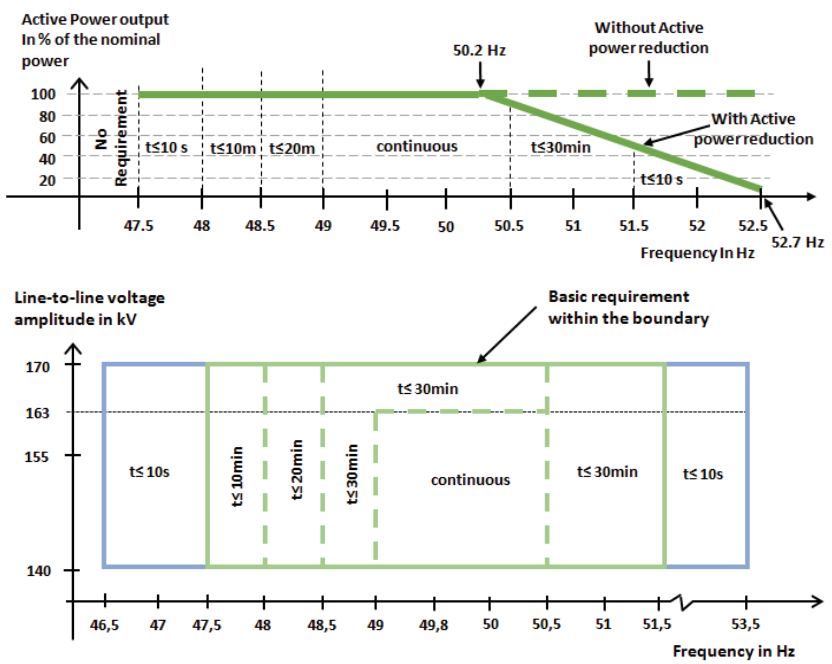

Fig. 3. Requirement for active power output for wind farm offshore 


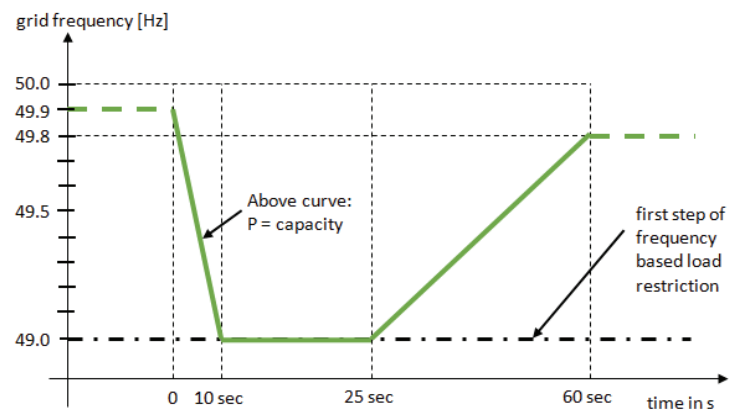

Fig. 4. Requirement for active power output during frequency range $49 \mathrm{~Hz} \sim 50 \mathrm{~Hz}$

PCC, wind farm can be disconnected from power system after 20 s with the active power output range $80 \% \sim 100 \%$.

\subsubsection{Tennet grid code}

The different requirements are applied to wind farms onshore and offshore. The frequency range for wind farm offshore is severe (Fig. 3) than onshore.

- Wind farm onshore (light green line) : 47.5 51.5Hz

- Wind farm offshore (gray line) : 46.5 53.5Hz

\subsubsection{SDL grid code}

SDL grid code is same with Tennet requirements for frequency and voltage deviations. However, the minimum limit for active power output to control frequency is added with duration time (Fig. 4).

\subsubsection{Korean grid code}

The tolerance of voltage deviation is specified in "The standard for electrical power system reliability and power quality" while the tolerance of frequency deviation is specified in "The provision for using transmission and distribution systems".

- Voltage deviation: - 765kV : $765 \pm 5 \%$

$$
\begin{aligned}
& -345 \mathrm{kV}: 345 \pm 5 \% \\
& -154 \mathrm{kV}: 154 \pm 10 \%
\end{aligned}
$$

- Frequency deviation: $57.5 \sim 62 \mathrm{~Hz}$

\subsection{Frequency control}

When wind farm supply to partial area due to fault on power systems, the over frequency may be occurred. Therefore, the active power output for frequency control is needed as follows.

\subsubsection{Energinet grid code}

The requirement for frequency control is as follows and is displayed in Fig. 5.

- The active power output must start to be controlled at $f_{3}$ and over.
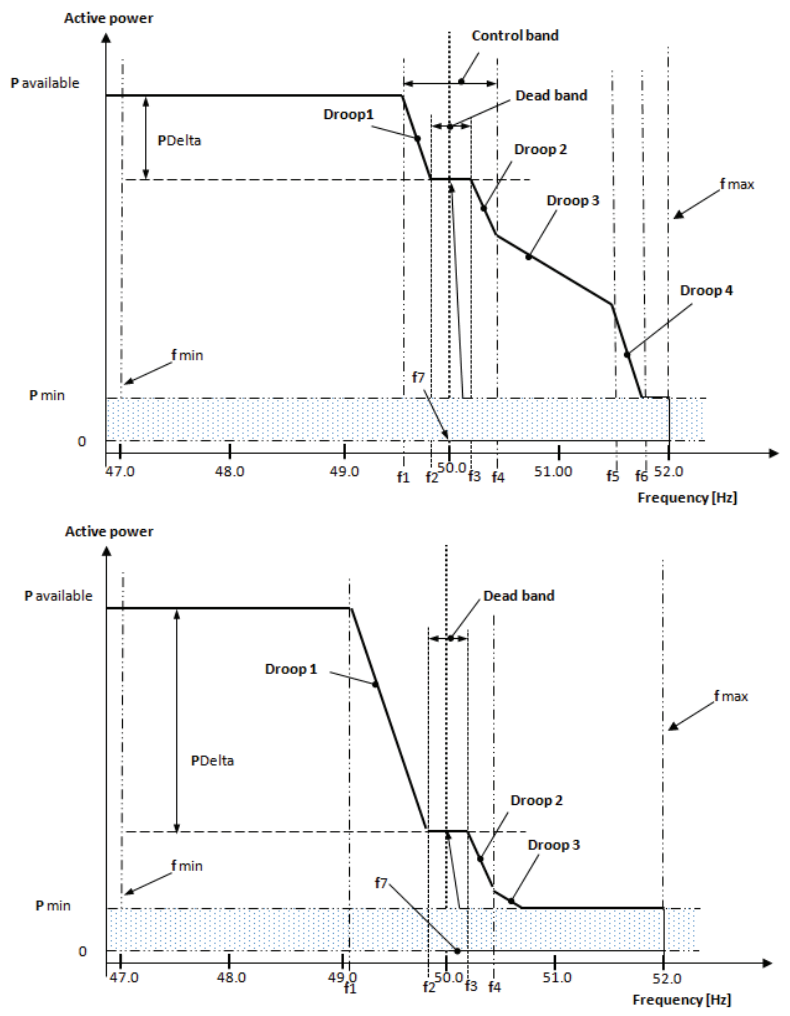

Fig. 5. Requirement for frequency control methods (minor downward regulation (above figure), major downward regulation (below figure))

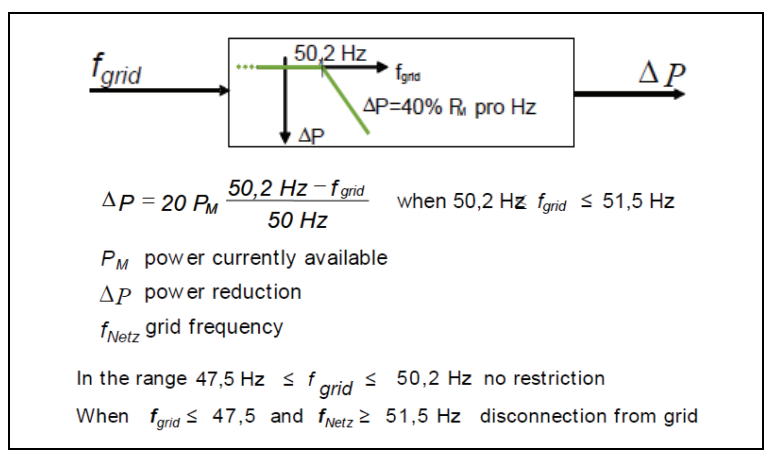

Fig. 6. Requirement for frequency control

- The active power output must be controlled for $\mathrm{f}_{\min } \sim$ $\mathrm{f}_{\max }$ at PCC

- If the active power output is below $\mathrm{P}_{\min }$, each wind turbine can be stopped.

\subsubsection{Tennet grid code}

The reduction ratio of active power output per $\mathrm{Hz}$ is same for wind farms onshore/offshore. The active power output must start to be controlled when PCC frequency is over $50.2 \mathrm{~Hz}$. However, the frequency range that needs active power control is different.

- Wind farm onshore : 50.2 51.5Hz (Fig. 6)

- Wind farm offshore : $50.2 \sim 52.7 \mathrm{~Hz}$ 
Table 2. Requirement for active power control

\begin{tabular}{c|c|c|c|c|c|c}
\hline \multirow{2}{*}{ Grid code } & \multicolumn{2}{|c|}{ Minimum power limit } & \multicolumn{2}{|c|}{ Frequency control } & \multicolumn{2}{c}{ Ramping down } \\
\cline { 2 - 7 } & $\begin{array}{c}\text { Frequency range } \\
(\mathrm{Hz})\end{array}$ & $\begin{array}{c}\text { Constant power control } \\
\text { (of rated power) }\end{array}$ & Start & Rate (of rated power) & Rate (of rated power) & Function time \\
\hline Energinet & $47 \sim 49.5$ & - & Fig.5 & Droop 1 4 & $>80 \%$ & $\leq 2 \mathrm{secs}$ \\
\hline Tennet & $47.5 \sim 49.5$ & $1 \% / \mathrm{min}$ & $>50.2$ & $40 \% / \mathrm{Hz}$ & $\geq 10 \%$ & $\leq 1 \mathrm{~min}$ \\
\hline SDL & $47.5 \sim 49.5$ & $1 \% / \mathrm{min}$ & $>50.2$ & $40 \% / \mathrm{Hz}$ & - & - \\
\hline Korea & - & - & - & - & $>80 \%$ & $\leq 5 \mathrm{secs}$ \\
\hline
\end{tabular}

\subsubsection{SDL grid code}

The requirements for frequency control are same with Tennet Grid Code.

\subsubsection{Korean grid code}

The grid code specify that active power output must be controlled with function of PCC frequency, however the reduction ratio of active power output per $\mathrm{Hz}$ does not be specified.

\subsection{Active power constraints}

With regard to fault on power system, the unbalance between supply and demand due to rearrangement needs active power output control of wind farm. That is, the active power output of wind farm must be controlled considering power system state.

\subsubsection{Energinet grid code}

The grid code includes absolute production constraint, delta production constraint and power gradient constraint (Fig. 7). An absolute production constraint is used to avoid overloading and active power output of wind farm is constrained to a predefined MW. A delta production constraint is used to control frequency and active power output of wind farm is constrained in proportion to the possible active power. A power gradient constraint is used to limit a rapid increase of active power output and active power output can increase with the maximum speed. The accuracy of the control and of the setpoint must not deviate by more than $\pm 2 \%$ of the setpoint value or by $\pm 0.5 \%$ of the rated power, depending on which yields the highest tolerance.

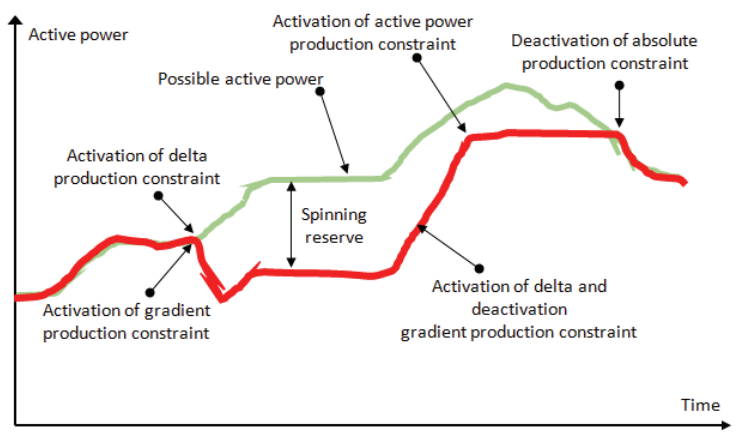

Fig. 7. Active power constraints

\subsubsection{Tennet grid code}

The grid code does not present a requirement for the active power output considering power system state.

\subsubsection{SDL grid code}

The grid code does not present a requirement for the active power output considering power system state

\subsubsection{Korean grid code}

The grid code has requirements for the active power output considering power system state as Energinet grid code. The grid code includes system protection constraint, absolute production constraint and power gradient constraint. A system protection constraint is used to avoid power system collapse and active power output of wind farm must be constrained to $20 \%$ of the rated power within $5 \mathrm{~s}$. An absolute production constraint is used to avoid overloading and the $10 \mathrm{~min}$ average active power output of wind farm is constrained to a predefined MW. A power gradient constraint is used to limit a rapid increase of active power output and active power output can increase with $10 \%$ of the rated power per $1 \mathrm{~min}$.

\section{Conclusion}

The grid code defines technical requirements that power plant must meet to ensure functions of power systems. Through grid code, the electrical grid stability can be maintained even if the large size wind farms are introduced into electrical grid. Absolutely, every power plant including renewable energies has to comply with the grid code to sell electricity to utilities. Therefore, a well-defined grid code shall be presented so as that there is no interpret the grid code by manufacturer, developer and TSO. Typical requirement of grid code is active power control that impacts on revenue for wind farm power output. Generally, the active power output of wind farm must be controlled to tolerate voltage and frequency deviations, control over frequency and be constrained considering power system state. The proper requirements regard of setpoint, duration time, accuracy and operating function must be necessarily specified considering power system state in grid code. 


\section{Acknowledgements}

This work was supported by the New \& Renewable Energy Core Technology Program of the Korea Institute of Energy Technology Evaluation and Planning (KETEP), granted financial resource from the Ministry of Trade, Industry \& Energy, Republic of Korea. (No. 2011 $\mathrm{T} 100200064)$

\section{References}

[1] T. Ackermann (Editor), Wind Power in Power Systems. (2ed.) John Wiley \& Sons, 2012.

[2] Gimenez Alvarez J.M and Molina, M.G, "Technical and Regulatory Exigencies for Grid Integration of Wind Generation", Cuarto Congreso Nacional, 10252, 2011.

[3] Inigo Martinez de Alegria, Jon Andreua, Jose Luis Martın, Pedro Ibanez, Jose Luis Villate, Haritza Camblong, "Connection requirements for wind farms: A survey on technical requierements and regulation", ELSEVIER, 2006.

[4] Mr Stamatios Chondrogiannis, Dr Mike Barnes, Dr Mark Osborne, Dr Liangzhong Yao, Mr Masoud Bazargan, Mr. Antony Johnson, "GRID COMPLIANT AC CONNECTION OF LARGE OFFSHORE WIND FARMS USING A STATCOM".

[5] Seung-Il Moon, Gi-Chan Pyo, and Jin-Woo Park, "Study on development of Grid code and operation scheme of Jeju Island with high wind penetration" .

[6] ECAR Ltd., "Wind Integration: International Experience WP2: Review of Grid Codes", 2011.

[7] Romain Castel, "Connection of offshore wind farms to the grid in Europe and Brittany", 2010.

[8] Elforsk rapport, "DC Connected Wind Farm", 2008.

[9] Jacob Aho, Andrew Buckspan, Jason Laks, Paul Fleming, Yunho Jeong, "A Tutorial of Wind Turbine Control for Supporting Grid Frequency through Active Power Control", NREL, 2012.

[10] A. Basit, A. D. Hansen, I. D. Margaris, J. C. Hansen, "A Review of Grid Requirements for Wind Farm in Denmark and China", China wind power 2012 conference, 2012.

[11] ENERGINET, "Technical regulation 3.2.5 for wind power plants with a power output greater than 11 kW", 2010.

[12] Tennet, "Grid Code-High and extra high voltage -", 2012.

[13] Tennet, "Requirements for Offshore Grid Connections in the Grid of TenneT TSO GmbH", 2012.

[14] BWE, "German Grid Code Requirements", 2008.

[15] KEPCO, "The provision for using transmission and distribution systems", 2013.

[16] Korean ministry of trade, industry and energy, "The standard for electrical power system reliability and power quality", 2012.

[17] EWEA, "Generic Grid Code Format for Wind Power Plants", 2009.

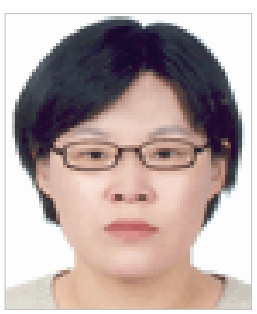

Mi-Young Kim She received her M.S. degree from Korea University of Technology and Education in 2005, and Ph.D. in Electrical Engineering from Hokkaido University in 2008. She has been a research engineer since 2013 in the Green and Industrial Technology Center, Innovation KR. Her research interests cover the distributed or renewable energies, electrical components of wind turbine, offshore substation, grid connection and new power systems.

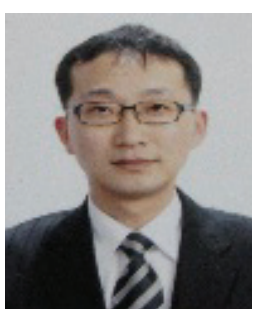

Yong-Un Song He received his M.S. degree from Korea University of Technology and Education in 2008. He has been a research engineer since 2013 in the Green and Industrial Technology Center, Innovation KR. His research interests cover the distributed or renewable energies, power electronics of wind turbine, HVDC system and new power systems. 